\title{
Mitral valve prolapse imaging: the role of tissue characterization
}

\author{
Silvia Pradella, Giulia Grazzini, Vittorio Miele \\ Department of Radiology, Azienda Ospedaliero-Universitaria Careggi, Florence, Italy \\ Correspondence to: Silvia Pradella, MD, PhD. Department of Radiology, Azienda Ospedaliero-Universitaria Careggi, Florence, Italy. \\ Email: pradellas@aou-careggi.toscana.it.
}

Comment on: Miller MA, Adams DH, Pandis D, Robson PM, Pawale A, Pyzik R, Liao SL, El-Eshmawi A, Boateng P, Garg J, Waterford S, Weiner MM, Dukkipati SR, Reddy VY, Fayad ZA, Trivieri MG. Hybrid Positron Emission Tomography/Magnetic Resonance Imaging in Arrhythmic Mitral Valve Prolapse. JAMA Cardiol 2020;5:1000-5.

Submitted Jul 30, 2020. Accepted for publication Aug 15, 2020.

doi: 10.21037/qims-2020-25

View this article at: http://dx.doi.org/10.21037/qims-2020-25

The presence of a mitral valve prolapse (MVP) is a common finding (up to $3 \%$ of the general population) but the correct classification of this pathology can be complex (1-3). MVP is classically defined as the displacement of the mitral single-leaflet or bileaflet $>2 \mathrm{~mm}$ beyond the longaxis annular plane at end-systole (4). The detection of this pathology occurs frequently during the clinical examination and is confirmed with two-dimensional echocardiography. Cardiac magnetic resonance (CMR) is recommended by the American Heart Association as an alternative imaging technique when the quality of ultrasound images is not appropriate $(5,6)$. In fact, CMR is a non-invasive imaging method that allows for a precise evaluation of ventricular volumes, systolic function, valvular morphology and the degree of mitral regurgitation. Furthermore, CMR provides a tissue characterization highlighting areas of myocardial injury/fibrosis with late gadolinium enhancement (LGE) and T1 mapping sequences and myocardial edema with T2weighted and T2 mapping sequences $(4,7)$.

MVP has a widely heterogenous outcome that ranges from a benign condition without the need for intervention, to severe complications $(8,9)$. MVP is an important cause of mitral regurgitation and it is estimated that almost $10 \%$ of subjects with MVP have severe mitral regurgitation requiring surgery $(1,10)$. Other adverse sequelae of primary MVP include congestive heart failure, infective endocarditis, stroke, arrhythmias and sudden cardiac death (SCD) $(2,5)$. The small subset of MVP patients with an increased risk of life-threatening ventricular arrhythmias and SCD are classified as having a malignant arrhythmic MVP phenotypic $(5,10)$. Usually, the 'arrhythmic MVP profile' is characterized by bileaflet MVP, myxomatous degeneration of the mitral valve (defined as leaflet thickness of greater than $5 \mathrm{~mm}$ due to the accumulation of proteoglycans), ECG repolarization abnormalities and complex ventricular arrhythmias (3).

Although the existence of malignant arrhythmic MVP is now recognized, its prevalence, risk stratification, and appropriate management have not been fully defined. In the Framingham study, the prevalence of MVP among SCD victims was reported to be $2.4 \%$ (11). Although the estimated risk of SCD in patients with MVP is low $(0.2 \%$ to $0.4 \%$ per year), it is at least 3 -fold higher than in the general population $(3,5,12,13)$. In light of this, the main clinical challenge is to identify MVP patients at higher risk for fatal arrhythmic events. Therefore, it is essential that the arrhythmogenic mechanism is better understood and also is crucial to identify the best imaging technique for risk stratification.

ECG abnormalities of "arrhythmic MVP" syndrome include complex premature ventricular beats (PVBs) arising from the papillary muscle region, the outflow tract, and from the Purkinje tissue. Moreover, inverted or biphasic T-wave inversions in the inferolateral leads are frequent in MVP patients who have had a cardiac arrest. These ECG findings suggest a stretch-mediated triggered activity. A mechanical irritation produced by the prolapsing leaflets on the papillary muscles and left ventricular (LV) outflow tract 
produces myocardial scarring that could be the substrate of electrical instability $(3,5,9)$. Basso et al. were the first to demonstrate the evidence of LV inferobasal fibrosis $(93 \%)$ or papillary muscle fibrosis $(88 \%)$ in young SCD victims with MVP. In fact, in a study subpopulation of living MVP patients with complex ventricular arrhythmias, CMR showed an LGE distribution very similar to histopathological fibrosis observed in SCD victims (8). Subsequently, these results have been confirmed by other studies, one of which demonstrated the association between MVP and myocardial fibrosis when comparing patients with MVP or non-MVP-related mitral regurgitation $(14,15)$. The authors found that left ventricle fibrosis is more frequent in MVP patients (36.7\%) compared with nonMVP patients (6.7\%), and that LV fibrosis tends to occur in the basal inferolateral wall and is associated with arrhythmic events. In this setting, CMR plays a pivotal role in identifying replacement-type fibrosis as variable patterns of LGE (MidWall, patchy, or subendocardial) in left ventricle inferobasal and at the level of papillary muscles. Moreover, CMR offers the capability to detect diffuse subclinical interstitial fibrosis by using T1 mapping. Bui et al. showed that patients with MVP had significantly shorter postcontrast $\mathrm{T} 1$ times when compared with controls, and diffuse (non-focal) subclinical ventricular fibrosis was associated with complex ventricular arrhythmia (16).

In addition, in our series of patients with MVP we found higher $\mathrm{T} 1$ values in native $\mathrm{T} 1$ maps and an increased extracellular volume compared with the control group. Furthermore, we found no statistically significant differences in terms of native $\mathrm{T} 1$ time at the inferolateral wall between MVP patients with LGE and those without LGE (17). These observations strengthened the assumption that in MVP, subclinical diffuse fibrosis may be a precursor of focal fibrosis or a separate disease entity, and confirmed that T1 mapping is a new promising tool for the identification of even non-focal myocardial wall alteration and for a better risk stratification of these patients.

Moreover, mitral insufficiency is the most frequent complication of MVP. This condition can cause atrial dilatation, which can be associated with atrial fibrillation (18). Atrial dilatation promotes the development of supraventricular arrhythmias. Recently, mitral annulus disjunction (MAD) was also considered to have a role in the arrhythmogenic mechanism. MAD is defined as the systolic separation of the point of insertion of the posterior mitral valve leaflet and left atrial junction from the left ventricle attachment at the posterior wall (3). Hutchins et al. first suggested that MAD could lead to myxomatous valve degeneration as a consequence of mechanical stress on the leaflets due to excessive mobility (19). Eriksson et al. and Carmo et al. demonstrated that MAD was associated with an increased risk of ventricular arrhythmias (20,21).

Perazzolo Marra et al. found that MAD was associated with arrhythmic MVP and left ventricle fibrosis (15). In addition, MAD is typically associated with the curling systolic motion of the mitral annulus (3). Since patients with arrhythmic MVP tend to present with MAD, systolic curling, myxomatous degeneration of the mitral valve apparatus and myocardial fibrosis, a cascade of events has been hypothesized. It is well known that the genesis of lifethreatening arrhythmias usually recognizes the combination of trigger and substrate eliciting PVBs. MAD with curling was suggested as the "trigger" able to increase annulus diameter during systole, and to cause a myxomatous valve degeneration and a mechanical stretch in the inferolateral myocardium and papillary muscle. Myocardial fibrosis, suggested as the "substrate", develops as result of this continuous wall stress exerted by the prolapsing leaflet with primary morphofunctional abnormality (3).

In the article by Miller et al. (22) "Hybrid Positron Emission Tomography/Magnetic Resonance Imaging in Arrhythmic Mitral Valve Prolapse", the authors hypothesized that patients with MVP and severe/ moderate-severe mitral regurgitation have an inflammatory component in addition to myocardial fibrosis. In their prospective observational study, the authors analyzed 20 MVP patients referred for mitral valve repair and who underwent hybrid positron emission tomography/magnetic resonance imaging (PET/MRI), an imaging modality that allows for simultaneous cardiac fluorine 18-labelled fluorodeoxyglucose $\left({ }^{18} \mathrm{~F}\right.$-FDG) PET and MRI with LGE imaging. The cohort study included 12 patients with complex ventricular arrhythmias (c-VA) and eight patients with minor ventricular arrhythmias (m-VA). The authors of the study found that $85 \%$ of their MVP patients with degenerative mitral regurgitation showed myocardial FDG uptake, and 70\% exhibited both myocardial FDG uptake and LGE. In addition, the segments of FDG uptake frequently matched with areas of myocardial fibrosis. Based on their findings, the authors suggested that the inflammatory component could be prodromal to the development of myocardial fibrosis in MVP.

In the last decade, the potential link between myocardial inflammation and cardiac arrhythmias has been investigated. Acute inflammation may lead to a direct myocyte injury 
with consequent replacement fibrosis that is able to sustain re-entrant circuits. However, inflammation also contributes to the development of VAs per se, releasing inflammatory cytokines that are involved in electrical remodelling of myocytes promoting various forms of arrhythmias $(23,24)$. Tung and colleagues have demonstrated the presence of occult inflammation on FDG PET in nearly $50 \%$ of patients referred for management of unexplained VAs. In the subgroup of patients that underwent endomyocardial biopsy, histologic diagnosis revealed non-granulomatous inflammation in $30 \%$, cardiac sarcoidosis in $60 \%$, and no inflammatory infiltrate in $10 \%$ of cases (25). These data have been confirmed by another single-center study that found abnormal myocardial ${ }^{18} \mathrm{~F}-\mathrm{FDG}$ uptake in $51 \%$ of patients with PVCs of unexplained cause (26).

Since myocardial inflammation is a possible arrhythmogenic substrate, the results of Miller and colleagues are interesting in terms of risk stratification and management of patients with MVP. However, to the best of our knowledge, no study has demonstrated the presence of an inflammatory component in MVP confirmed by histopathological analysis. In addition, regional myocardial ${ }^{18} \mathrm{~F}$-FDG uptake is not specific to inflammation since it can also reflect myocardial ischemia, as the study authors indicated (27).

Another complication in the interpretation of ${ }^{18} \mathrm{~F}$-FDGPET findings is that an inadequate suppression of physiologic myocardial uptake of ${ }^{18} \mathrm{~F}$-FDG may lead to false positive results. Moreover, a selective FDG uptake in the left ventricle inferolateral wall is considered a normal physiologic pattern (24). In this setting, to improve the specificity, ${ }^{18} \mathrm{~F}$-FDGPET results should be compared with T2-weighted CMR images to detect myocardial edema, and with LGE images to detect myocardial injury/fibrosis. However, Miller et al. did not compare FDG uptake with T2-weighted images in their study. Since T2 mapping is the most specific CMR parameter for acute inflammation (28), studies comparing ${ }^{18} \mathrm{~F}$-FDGPET findings with myocardial $\mathrm{T} 2$ relaxation time (increased in presence of acute myocardial edema) could be very interesting.

Others limitations of Miller's article are highlighted by the authors themselves, such as the small number of patients. In our opinion, the selection bias is one of the most important limitations. The authors selected only patients with significant mitral regurgitation referred for mitral valve surgery. However, in our study evaluating the association of LGE with the mitral regurgitation fraction in MVP patients, we demonstrated that LGE is independent of the degree of valve dysfunction. Myocardial focal fibrosis was found even in patients with mild mitral regurgitation, and no significant differences were found in the severity of mitral regurgitation among MVP patients with LGE (33\% mild, $40 \%$ moderate and $27 \%$ severe mitral regurgitation) (17). Furthermore, SCD or life-threatening arrhythmias can also occur in patients with hemodynamically uncomplicated MVP $(3,9)$. Finally, a high degree of valve regurgitation and left ventricle remodeling are considered independent predictors of SCD and ventricular arrhythmias in MVP $(3,8,9)$. In other words, the authors independently selected a high-risk population according to the presence or absence of myocardial inflammation or fibrosis, and excluded MVP patients with absent or mild mitral regurgitation which may present an arrhythmogenic substrate, regardless of the degree of valve dysfunction.

In conclusion, we have some questions concerning the three patients that exhibited only focal FDG uptake in the absence of any LGE: what kind of VAs (complex or minor ventricular arrhythmias) do they have? What is the degree of valve regurgitation (3 or 4)? Are these patients symptomatic or asymptomatic? Do they present left ventricle remodeling or not? This information would be informative and help us to understand better if myocardial inflammation could represent an early stage of a progressive disease process.

\section{Acknowledgments}

Funding: None.

\section{Footnote}

Provenance and Peer Review: This article was commissioned by the editorial office, Quantitative Imaging in Medicine and Surgery. The article did not undergo external peer review.

Conflicts of Interest: The authors have completed the ICMJE uniform disclosure form (available at http://dx.doi. org/10.21037/qims-2020-25). The authors have no conflicts of interest to declare.

Open Access Statement: This is an Open Access article distributed in accordance with the Creative Commons Attribution-NonCommercial-NoDerivs 4.0 International License (CC BY-NC-ND 4.0), which permits the noncommercial replication and distribution of the article with the strict proviso that no changes or edits are made and the 
original work is properly cited (including links to both the formal publication through the relevant DOI and the license). See: https://creativecommons.org/licenses/by-nc-nd/4.0/.

\section{References}

1. Freed LA, Levy D, Levine RA, Larson MG, Evans JC, Fuller DL, Lehman B, Benjamin EJ. Prevalence and clinical outcome of mitral-valve prolapse. N Engl J Med 1999;341:1-7.

2. Parwani P, Avierinos JF, Levine RA, Delling FN. Mitral Valve Prolapse: Multimodality Imaging and Genetic Insights. Prog Cardiovasc Dis 2017;60:361-9.

3. Basso C, Iliceto S, Thiene G, Perazzolo Marra M. Mitral Valve Prolapse, Ventricular Arrhythmias, and Sudden Death. Circulation 2019;140:952-64.

4. Han Y, Peters DC, Salton CJ, Bzymek D, Nezafat R, Goddu B, Kissinger KV, Zimetbaum PJ, Manning WJ, Yeon SB. Cardiovascular magnetic resonance characterization of mitral valve prolapse. JACC Cardiovasc Imaging 2008;1:294-303.

5. Muthukumar L, Jahangir A, Jan MF, Perez Moreno AC, Khandheria BK, Tajik AJ. Association Between Malignant Mitral Valve Prolapse and Sudden Cardiac Death: A Review. JAMA Cardiol 2020;5:1053-61.

6. Nishimura RA, Carabello B. Operationalizing the 2014 ACC/AHA Guidelines for Valvular Heart Disease: A Guide for Clinicians. J Am Coll Cardiol 2016;67:2289-94.

7. Hamlin SA, Henry TS, Little BP, Lerakis S, Stillman AE. Mapping the future of cardiac MR imaging: case-based review of T1 and T2 mapping techniques. Radiographics 2014;34:1594-611.

8. Basso C, Perazzolo Marra M, Rizzo S, De Lazzari M, Giorgi B, Cipriani A, Frigo AC, Rigato I, Migliore F, Pilichou K, Bertaglia E, Cacciavillani L, Bauce B, Corrado D, Thiene G, Iliceto S. Arrhythmic Mitral Valve Prolapse and Sudden Cardiac Death. Circulation 2015;132:556-66.

9. Miller MA, Dukkipati SR, Turagam M, Liao SL, Adams DH, Reddy VY. Arrhythmic Mitral Valve Prolapse: JACC Review Topic of the Week. J Am Coll Cardiol 2018;72:2904-14.

10. Perazzolo Marra M, Basso C. Mechanical dispersion and arrhythmic mitral valve prolapse: substrate and trigger in electrical instability. Heart 2019;105:1053-4.

11. Narayanan K, Uy-Evanado A, Teodorescu C, Reinier K, Nichols GA, Gunson K, Jui J, Chugh SS. Mitral valve prolapse and sudden cardiac arrest in the community. Heart Rhythm 2016;13:498-503.
12. Nishimura RA, McGoon MD, Shub C, Miller FA Jr, Ilstrup DM, Tajik AJ. Echocardiographically documented mitral-valve prolapse. Long-term follow-up of 237 patients. N Engl J Med 1985;313:1305-9.

13. Boudoulas H, Schaal SF, Stang JM, Fontana ME, Kolibash AJ, Wooley CF. Mitral valve prolapse: cardiac arrest with long-term survival. Int J Cardiol 1990;26:37-44.

14. Kitkungvan D, Nabi F, Kim RJ, Bonow RO, Khan MA, Xu J, Little SH, Quinones MA, Lawrie GM, Zoghbi WA, Shah DJ. Myocardial Fibrosis in Patients With Primary Mitral Regurgitation With and Without Prolapse. J Am Coll Cardiol 2018;72:823-34.

15. Perazzolo Marra M, Basso C, De Lazzari M, Rizzo S, Cipriani A, Giorgi B, Lacognata C, Rigato I, Migliore F, Pilichou K, Cacciavillani L, Bertaglia E, Frigo AC, Bauce B, Corrado D, Thiene G, Iliceto S. Morphofunctional Abnormalities of Mitral Annulus and Arrhythmic Mitral Valve Prolapse. Circ Cardiovasc Imaging 2016;9:e005030.

16. Bui AH, Roujol S, Foppa M, Kissinger KV, Goddu B, Hauser TH, Zimetbaum PJ, Ngo LH, Manning WJ, Nezafat R, Delling FN. Diffuse myocardial fibrosis in patients with mitral valve prolapse and ventricular arrhythmia. Heart 2017;103:204-9.

17. Pradella S, Grazzini G, Brandani M, Calistri L, Nardi C, Mori F, Miele V, Colagrande S. Cardiac magnetic resonance in patients with mitral valve prolapse: Focus on late gadolinium enhancement and T1 mapping. Eur Radiol 2019;29:1546-54.

18. Borger MA, Mansour MC, Levine RA. Atrial Fibrillation and Mitral Valve Prolapse: Time to Intervene? J Am Coll Cardiol 2019;73:275-7.

19. Hutchins GM, Moore GW, Skoog DK. The association of floppy mitral valve with disjunction of the mitral annulus fibrosus. N Engl J Med 1986;314:535-40.

20. Eriksson MJ, Bitkover CY, Omran AS, David TE, Ivanov J, Ali MJ, Woo A, Siu SC, Rakowski H. Mitral annular disjunction in advanced myxomatous mitral valve disease: echocardiographic detection and surgical correction. J Am Soc Echocardiogr 2005;18:1014-22.

21. Carmo P, Andrade MJ, Aguiar C, Rodrigues R, Gouveia $\mathrm{R}$, Silva JA. Mitral annular disjunction in myxomatous mitral valve disease: a relevant abnormality recognizable by transthoracic echocardiography. Cardiovasc Ultrasound 2010;8:53.

22. Miller MA, Adams DH, Pandis D, Robson PM, Pawale A, Pyzik R, Liao SL, El-Eshmawi A, Boateng P, Garg J, Waterford S, Weiner MM, Dukkipati SR, Reddy VY, Fayad ZA, Trivieri MG. Hybrid Positron Emission 
Tomography/Magnetic Resonance Imaging in Arrhythmic Mitral Valve Prolapse. JAMA Cardiol 2020;5:1000-5.

23. Yalta T, Yalta K. Systemic Inflammation and Arrhythmogenesis: A Review of Mechanistic and Clinical Perspectives. Angiology 2018;69:288-96.

24. Muser D, Castro SA, Alavi A, Santangeli P. Potential Role of PET in Assessing Ventricular Arrhythmias. PET Clin 2019;14:281-91.

25. Tung R, Bauer B, Schelbert H, Lynch JP 3rd, Auerbach M, Gupta P, Schiepers C, Chan S, Ferris J, Barrio M, Ajijola O, Bradfield J, Shivkumar K. Incidence of abnormal positron emission tomography in patients with unexplained cardiomyopathy and ventricular arrhythmias: The potential role of occult inflammation in arrhythmogenesis. Heart Rhythm 2015;12:2488-98.

26. Lakkireddy D, Turagam MK, Yarlagadda B, Dar T, Hamblin M, Krause M, Parikh V, Bommana S, Atkins D, Di Biase L, Mohanty S, Rosamond T, Carroll H, Nydegger C, Wetzel L, Gopinathannair R, Natale A. Myocarditis Causing Premature Ventricular Contractions:
Insights From the MAVERIC Registry. Circ Arrhythm Electrophysiol 2019;12:e007520.

27. Nensa F, Bamberg F, Rischpler C, Menezes L, Poeppel TD, la Fougère C, Beitzke D, Rasul S, Loewe C, Nikolaou K, Bucerius J, Kjaer A, Gutberlet M, Prakken NH, Vliegenthart R, Slart RHJA, Nekolla SG, Lassen ML, Pichler BJ, Schlosser T, Jacquier A, Quick HH, Schäfers M, Hacker M; European Society of Cardiovascular Radiology (ESCR); European Association of Nuclear Medicine (EANM) Cardiovascular Committee. Hybrid cardiac imaging using PET/MRI: a joint position statement by the European Society of Cardiovascular Radiology (ESCR) and the European Association of Nuclear Medicine (EANM). Eur Radiol 2018;28:4086-101.

28. Ferreira VM, Schulz-Menger J, Holmvang G, Kramer CM, Carbone I, Sechtem U, Kindermann I, Gutberlet M, Cooper LT, Liu P, Friedrich MG. Cardiovascular Magnetic Resonance in Nonischemic Myocardial Inflammation: Expert Recommendations. J Am Coll Cardiol 2018;72:3158-76.
Cite this article as: Pradella S, Grazzini G, Miele V. Mitral valve prolapse imaging: the role of tissue characterization. Quant Imaging Med Surg 2020;10(12):2396-2400. doi: 10.21037/qims-2020-25 